\title{
Comparison of clinical and manometric parameters in Achalasia cardia between elderly and non-elderly patients in West Bengal.
}

\author{
${ }^{1}$ Dr. Ashis Kumar Saha, ${ }^{2}$ Dr. Gautam Chatterjee., ${ }^{3}$ Dr. Subhas Chandra Hazra. \\ ${ }^{I}$ M.D.(Cal), D.T.M \& H (Cal) Assistant Professor, Department of Medicine, K P C Medical College, Jadavpur, \\ Kolkata, West Bengal \\ ${ }^{2}$ M.D.(Cal). Dip Card (Cal). Assistant Professor, Department of Medicine, K P C Medical College, Jadavpur, \\ Kolkata, West Bengal \\ ${ }^{3}$ M.D.(Cal). Professor \& Head of the Department of Medicine, K P C Medical College, Jadavpur, Kolkata, West \\ Bengal
}

\begin{abstract}
Achalasia cardia, a primary esophageal motility disorder of unknown etiology involving lower twothird of esophagus and lower esophageal sphincter (LES), can be specifically diagnosed by gold standard method, manometry, which shows abnormal LES relaxation and absent or vigorous peristalsis. In our study, 125 patients were admitted with dysphagia, regurgitation of food, vomiting, chest pain, retrosternal discomfort, of which, 36 were detected as esophageal carcinoma and lye stricture, rest were non organic. These 89 patients were sent for esophageal manometry. Males were significantly affected than females. Other than dysphagia, common symptoms were regurgitation of food and chest pain. $59.55 \%$ patients demonstrated LES pressure <45 mm of Hg. Rest had hypertensive LES. Maximum contraction amplitude was detected in $61.79 \%$ of patients (vigorous Achalasia). We also compared symptoms and manometric parameters in two group of patients (one was $\leq 60$ years and second one was $>60$ years). Incidence of duration of symptoms before diagnosis and vomiting were significant in elderly patients, but manometric parameters showed no significant difference. Basal LES pressure was above normal in our study.
\end{abstract}

Key-words: Achalasia cardia, esophagus, endoscopy, barium study, esophageal manometry, lower esophageal sphincter, esophageal peristalsis

\section{Introduction:}

Achalasia is a primary esophageal disorder of unknown etiology, involving lower two-third of the esophageal body and lower esophageal sphincter (LES) - it is characterized manometrically by insufficient or absence of relaxation of LES, along with esophageal aperistalsis or sometimes vigorous peristalsis of the lower two-third of the esophageal body. Sometimes, there may be increased basal intraesophageal pressure which is more than intragastric pressure and LES pressure ${ }^{1}$. Incidence of Achalasia is equal in both sexes and ages ${ }^{2}$. Degeneration of myenteric plexus results in lack of nitric oxide producing inhibitory neurons needed for coordination of LES relaxation and peristaltic contraction of the esophagus ${ }^{3,4,5,6,7}$.This neurodegenerative changes may be of inflammatory origin, which may be due to viral involvement, but genetic, autoimmune or other infective causes cannot be ruled out ${ }^{7}$.The cause of neurodegeneration in secondary Achalasia is mainly due to Trypanosoma cruzi infection producing Chagas disease, which is endemic in South America ${ }^{8}$. Again, pseudoachalasia is a term where there is loss of peristalsis, lack of LES relaxation mimicking Achalasia. The causes of pseudoachalasia may be adenocarcinoma of gastro-esophageal junction ${ }^{9}$, breast cancer, pancreatic cancer, histiocytosis $\mathrm{x}$, amyloidosis ${ }^{10,11}$. These patients usually present with dysphagia to both solid and liquid, regurgitation of food, chest pain, retrosternal discomfort and vomiting at different times, for which, they have to be investigated by barium swallow and/or upper gastrointestinal endoscopy and ultimately manometry. Our aim in this study was to compare the clinical and manometric findings between the patients having less or equal to and more than sixty years.

\section{Materials and methods:}

We started our extensive study only after getting permission from Ethical Committee of our institute. Total 125 patients were admitted in our K P C Medical College and Hospital with the symptoms of dysphagia to solid and liquid, retrosternal discomfort, vomiting, regurgitation of food, chest pain within the span of 5 years. After performing upper gastrointestinal endoscopy, 26 patients were diagnosed as esophageal or gastroesophageal carcinoma and 10 patients as lye stricture. Rest 89 patients were diagnosed clinically as possible Achalasia cardia by the evidence of the following endoscopic findings, such as, large accumulation of saliva and other secretions in the esophageal cavity and eccentricity of the esophageal cavity. Then, they underwent barium esophagogram, which showed smooth tapering at the distal esophagus with typical bird's beak appearance, dilatation of esophagus above the gastroesophageal junction, lack of primary peristaltic movement during 
fluoroscopic examination, accumulation of contrast column above the LES and impaired transit of barium through gastroesophageal junction. So, they were sent for esophageal manometry using 8 channels (8 recording points) perfused manometric system. During this procedure, the patient was on lateral recumbent position. By this machine, we collected the required manometric parameters, like, firstly, pressure in the upper esophageal sphincter, secondly, amplitude, shape, duration and progression velocity of esophageal contraction, thirdly, basal LES pressure, fourthly, relaxation of LES in response to swallowing of $5 \mathrm{ml}$. of water. For this, at least 10 swallows (speed at least 15 seconds apart) were tested. After collection of all the data, we demoed incidence of sex preponderance and compare symptoms in these patients. Again, we compared the symptoms and manometric parameters in the two groups of patients (group 1 was $\leq 60$ years, and group 2 was more than 60 years).

\section{Results:}

Male patients were significantly affected than females (51 vs. 38 respectively, $\mathrm{p}=0.02$ ). Common symptoms were recurrent dysphagia to solid and liquid $(n=100)$, regurgitation of food $(n=68)$, followed by vomiting $(n=28)$ and retrosternal discomfort $(n=22)$. Basal LES pressure of less than $45 \mathrm{~mm}$ of $\mathrm{Hg}$ were demonstrated in $59.55 \%(n=53)$ of patients, rest $40.44 \%(n=36)$ of patients had LES pressure more than $45 \mathrm{~mm}$ of $\mathrm{Hg}$. $37.07 \%$ patients $(\mathrm{n}=33)$ showed tight LES with no evidence of swallow induces relaxation. Whereas, $51.68 \%(\mathrm{n}=46)$ and $11.23 \% \quad(\mathrm{n}=10)$ patients demoed $1-30 \%$ and $50-30 \%$ swallow induced relaxation respectively. Again, 38.20\% $(n=34)$ patients demonstrated tubular aperistaltic esophagus, whereas, $61.79 \%$ patients $(n=55)$ showed hyperperistaltic changes. [Table 1]. When we compared the duration of symptoms before the definite diagnosis was made, nature of symptoms, manometric parameters of esophagus in the two groups of patients (one having $\leq 60$ years of age and $>60$ years of age), it was demonstrated that elderly patients significantly suffered from longer duration of symptoms $(\mathrm{p}=0.002)$, and vomiting $(\mathrm{n}=12 \mathrm{vs} . \mathrm{n}=16, \mathrm{p}=0.05)$. In case of manometric parameters, no difference was observed between the two groups [Table 2].

\section{Discussion:}

Achalasia cardia, a primary motor disorder of esophagus, in which, absence of peristalsis mainly in lower two-thirds (where there is smooth muscles) and impaired LES relaxation due to damage of myenteric plexus, are the major concern, but increased intraesophageal pressure with partial LES relaxation may be present. Pohl D. et al showed in their study that all ages and both sexes were equally affected ${ }^{2}$. Again, the above study showed the delay in the diagnosis from the beginning of the symptoms were 24 to 36 months $^{2}$, whereas, in our study, the duration of symptoms before coming to definite diagnosis were much higher in both age groups (41.51 \pm 42.5 months in $\leq 60$ years age vs. $52.5 \pm 64.8$ months in $>60$ years age). Duration of symptoms before reaching definite diagnosis was significantly higher in older age group than $\leq 60$ year's age group (52.5 \pm 64.8 months vs. $41.5 \pm 42.5, \mathrm{p}=0.002$ ) in our study, whereas, Ortiz-Olvera $\mathrm{N}$ et al. showed that duration of symptoms was greater in patients having $\leq 60$ years age than in the patients of $>60$ years of age ( 24 months vs. 12 months respectively, $\mathrm{p}=<0.05)^{12}$. In patient with symptom suggestive of dysphagia to both solid and liquid, endoscopy and radiologic studies are the $1^{\text {st }}$ and $2^{\text {nd }}$ lines of investigations. If these investigations are negative, manometry will be the $3^{\text {rd }}$ line of investigation, and it is the gold standard for the diagnosis of esophageal motility disorder ${ }^{2}$. Our study showed that swallow induced relaxation of LES in patients with Achalasia were less than 50\%, which were shown in studies done by Pandolfino JE et al, and Castell $\mathbf{J}^{13,14}$.

In the study done by Ortiz-Olvera $\mathrm{N}$ et al. it was shown that chest pain was more frequent in patients of $\leq 60$ years age than patients of $>60$ years $(51.2 \%$ vs. $22.2 \%, p=<0.03)$, whereas, in our study, both groups were similarly affected by chest pain in our study ( $42.85 \%$ vs. $40 \%$ respectively $)^{12}$.

Again, mean basal LES pressure was similar in both age groups in our studies as well as in the study done by Ortiz-Olvera $\mathrm{N}$ et $\mathrm{al}^{12}$. But the basal LES pressure in both groups was slightly higher in our study than in the study done by Agrawal A et al. $(42.82 \pm 20.92 \mathrm{~mm} \text { of } \mathrm{Hg} \text { vs. } 37.9 \pm 21.2 \mathrm{~mm} \text { of } \mathrm{Hg} \text {. })^{15}$.

Number of patients having hypertensive LES (LES $>45 \mathrm{~mm}$ of $\mathrm{Hg}$ were same in both age groups in our study $(\mathrm{n}=18, \mathrm{p}=0.21)$, whereas, in the study done by Ortiz-Olvera $\mathrm{N}$ et al. 21 patients had hypertensive LES, of which, 17 patients were $\leq 60$ years of age and only 4 patients $>60$ years having no statistical differences $(13.8 \%$ vs. $11 \%, \mathrm{p}=0.8)^{12}$.

Richter et al. demonstrated $70 \%$ to $81 \%$ patients had incomplete to no relaxation, but, in our study, $100 \%$ patients showed similar findings ${ }^{16}$. Maximal amplitude of esophageal contraction was similar in both age groups in our study as well as in other study ${ }^{12}$. Maximal amplitude of esophageal contraction in our study was seen in $61.79 \%$ of patients, which was similar to the study done by Agrawal A et al. The increased amplitude of contraction is the consequence of increased intraesophageal basal pressure above the intraabdominal pressure. As a result, retained esophageal contents will either enter into stomach cavity or will be regurgitated.

In our study, $38.20 \%$ patients $(n=34)$ showed manometric evidence of aperistalsis, whereas, $94.28 \%$ patients showed aperistaltic tubular esophagus in the study done by Dumitrascu DL et $\mathrm{al}^{17}$. 


\section{Conclusion:}

Males were significantly affected than females from Achalasia cardia. Duration of symptoms suffered from by the patients was significantly higher in elderly patients. All the patients were suffered from incomplete to no relaxation. Non elderly patients demonstrated significant non-relaxation than elderly patients. Maximum amplitude of contraction (vigorous Achalasia) was much higher in our patients Basal LES pressure was above normal in our study.

\section{References:}

[1] Holloway RH. Esophageal manometry. Review. GI Motility online[serial online] 2006 [cited September 2008]. Available from URL: http://www.nature.com/gimo/contents/pt/full/gimo30.html

[2] Pohl D, Yutuian R. Achalasia:an overview of diagnosis and treatment. J. Gastrointestin. Liver Dis 2007; 16(3):297-303.

[3] Mayberry JF. Epidemiology and demographics of Achalasia. Gastrointest Endosc. Clin N Am 2001; 11: 235-248.

[4] Podas T, Eaden J, Mayberry M, Mayberry J. Achalasia: a critical review of epidemiological studies. Am J Gastroenterl 1998; 93: 2345-2347.

[5] Duntemann TJ, Dresner DM. Achalasia-like syndrome presenting after highly selective vagotomy. Dig Dis Sci 1995; 40:2081-2083.

[6] Cassella RR, Brown AL, Sayre GP, Ellis FH. Achalasia of the esophagus: pathologic and etiologic consideration. Ann. Surg 1964; 160: 474-487.

[7] Park W, Vaezi MF. Etiology and pathogenesis of Achalasia. The current understanding. Am J Gastroenterol 2005; 100:1404-1414

[8] De Oliveira RB, Rezende Filho J, Dantas RO, Iazigi N. The spectrum of esophageal motor disorders in Chagas disease. Am J Gastroenterol 1995; 90: 1119-1124.

[9] Parkman HP, Cohen S. Malignancy induced secondary Achalasia. Dysphagia 1994; 9:292-296.

[10] De Borst JM, Wagtmans MJ, Fockens P, van Lanschot JJ, West R, Boeckxstaens GE. Pseudoachalasia caused by pancreatic carcinoma. Eur J Gastroenterol Hepatol 2003; 15:825-828.

[11] Portale G, Costantini M, Zaninotto G, et al. Pseudoachalasia: not only esophago-gastric cancer. Dis Esophagus 2007; 20:168-172.

[12] Ortiz-Olvera N, Gonzalez-Martinez M, Dehesa-Violante M, Moran-Vilota S. Clinical and manometric findings on elderly patients with Achalasia.

[13] Pandolfino JE. Kahril PJ. Amarican Gastroenterology Association. AGA technical review on the clinical use of esophageal manometry. Gastroenterology 2005; 128(1):209-224.

[14] Castell J. Esophageal manometry. In: Schuster Atlas of Gastrointestinal Motility 2002; 69-86.

[15] Agrawal A, Hila A, Tutuian R, Castell DO. Manometry and impedance characteristics of Achalasia. Facts and myths. 2008; 42(3):266-270.

[16] Richter JE. Oesophageal motility disorder. Lancet 2001; 358:823-826.

[17] Dumitrascu DL, Teodora SB, Liliana D. Esophageal Achalasia - Manometric Patterns. 2009; 47(3):243-247.

Table 1: Incidence of sex and symptoms in patients suffering from Achalasia cardia

\begin{tabular}{|l|l|l|l|}
\hline Item & Incidence & $\begin{array}{l}\text { Percentage } \\
\text { (in 89 patients) }\end{array}$ & P value \\
\cline { 1 - 3 } SEX & 51 & 57.30 & 0.0257 \\
\cline { 1 - 4 } Males & 38 & 42.69 & \\
\hline Females & & & \\
\hline SYMPTOMS & 68 & 76.40 & \\
\hline Regurgitation & 37 & 41.57 & \\
\hline Chest pain & 28 & 3146 & \\
\hline Vomiting & 22 & 24.71 & \\
\hline Retrosternal discomfort & 53 & 59.55 & \\
\hline Basal LES pressure $(-45 \mathrm{~mm}$ of $\mathrm{Hg})$. & 36 & 40.44 & \\
\hline Basal LES pressure $(>45 \mathrm{~mm}$ of $\mathrm{Hg})$. & 33 & 37.07 & \\
\hline No relaxation & 46 & 51.68 & \\
\hline $1-\leq 30 \%$ relaxation & 10 & 11.23 & \\
\hline$>30 \%$ relaxation & 55 & 61.79 & \\
\hline Maximum amplitude of contraction $(37 \mathrm{~mm}$ of $\mathrm{Hg}$.) & 34 & 38.20 & \\
\hline Aperistalsis & & & \\
\hline
\end{tabular}

Table 2: Comparison of duration of symptoms according to age:

\begin{tabular}{|l|l|l|l|}
\hline Items & $\begin{array}{l}\leq \mathbf{6 0} \text { years } \\
\mathbf{( 4 9 )}\end{array}$ & $\begin{array}{l}\text { >60 years } \\
\mathbf{( 4 0 )}\end{array}$ & P value \\
\hline Duration of symptoms (months) & $41.5 \pm 42.5$ & $52.5 \pm 64.8$ & 0.002 \\
\hline Regurgitations & 37 & 31 & 0.41 \\
\hline Chest pain & $21(42.85 \%)$ & $16(40 \%)$ & 0.39 \\
\hline Vomiting & 12 & 16 & 0.05 \\
\hline Retrosternal discomfort & 11 & 11 & 0.29 \\
\hline LES pressure <45 mm of Hg. & 31 & 22 & 0.21 \\
\hline LES pressure $>45 \mathrm{~mm}$ of $\mathrm{Hg}$. & 18 & 18 & 0.21 \\
\hline No relaxation & 22 & 11 & 0.04 \\
\hline Relaxation $(0--\leq 30 \%)$ & 23 & 23 & 0.16 \\
\hline Relaxation (>30\%) & 4 & 6 & 0.15 \\
\hline Maximum amplitude of contraction $(37 \mathrm{~mm}$ of Hg.) & 31 & 24 & 0.37 \\
\hline Aperistalsis & 18 & 16 & 0.37 \\
\hline
\end{tabular}

